\title{
About Innovation Practice Within Geometric-Graphic Training*
}

\author{
Irina Stolbova ${ }^{1[0000-0002-0546-9428]}$, Konstantin Nosover[0000-0002-3265-9091] \\ Perm National Research Polytechnic University, Perm, Russia \\ ${ }^{1}$ stolbova.irinalgmail.com, ${ }^{2}$ designconeya.ru
}

\begin{abstract}
The article discusses major problems associated with "digitalization" of higher professional education. The data on organization of the system of "mixed learning" and filling of traditional geometric- graphic education with electronic innovations are presented. The structural scheme of training is given taking into account technological innovations. Examples of training design tasks in the electronic learning environment for creating 3D models of geometric objects intended for students to perform as part of independent work are given. A positive effect was noted when students master new technologies, as well as difficulties in implementing the online - learning process are shown.
\end{abstract}

Keywords: Digitalization, Geometric-Graphic Training, Mixed Teaching, Design Assignments, 3D-Modeling, Online Technology

\section{Introduction}

Global digitalization of all spheres of society's life radically changes the model of design activity and, accordingly, leads to a change in the paradigm of engineering training. In the modern system of vocational education, the curriculum of technical disciplines should not lag behind the integrated workflow of accelerated production of an object, which is an organic combination of computer technology, three-dimensional modeling and engineering analysis, design, virtual engineering and modern manufacturing methods [1]. The task of acquiring trainees' information and communication technological skills and professional competencies based on modern information technologies is being actualized.

Already, many universities are actively engaged in "digitization" of their educational resources and predict the outcome of the updated teaching technology as improving the quality of training [2]. At the same time, effectiveness of such technologies should be determined not only by high-quality "digitization" of educational materials and modernization of their content, but also by creation of a developed system of network

Copyright (C) 2020 for this paper by its authors. Use permitted under Creative Commons License Attribution 4.0 International (CC BY 4.0).

* Publication financially supported by RFBR grant №18-08-01484 
services that ensure availability of educational resources and allow constant monitoring of student performance.

Currently, the transition to mixed learning is widely discussed, when in the framework of traditional classical teaching distance educational resources are applied, used by trainees independently in any place and at a convenient time. There is a steady trend of increasing hours of students' independent work by reducing the classroom load. However, the solution of issues of a rational combination of traditional education and communication educational innovations is at the experimental level.

The expert data presented in [1] and relating, in particular, to training bachelors at various stages of training for integrated engineering activities, show various combinations of volumes of full-time (collective work under the guidance of a teacher) and distance (independent work) training. For example, for successful training at the design stage of technical objects (development of algorithms, implementation of design documentation), the ratio of traditional learning and distance learning is fixed as 30\% to $70 \%$, respectively. However, the question of how this ratio changes with the development of a vocational training program from course to course, how various forms of educational activity correspond to it (lectures, practical exercises, laboratory practical work, students' independent work), remains open. In this regard, obtaining additional practical data on organization of an innovative education system is of interest. It is also necessary to take into account appropriateness of digital innovation in implementation of various areas of subject-based learning.

\section{The Need for Innovation in Geometric-Graphic Education}

One of the types of subject teaching is basic geometric-graphic training (GGT) for students of a technical university, the purpose of which is to form readiness of future graduates for design and development activities. Dynamic development of design as a type of engineering activity is explained by improving the capabilities of modern computer technologies and $\mathrm{CAD}$, updating the design engineer's functionality, increased requirements for the specialist's design culture, a systematic approach to engineering and technical support and digital support for all stages of the life cycle of technical objects [3].

Graphic disciplines (descriptive geometry, engineering graphics, computer graphics) at a technical university refer to general education and are the first professionally oriented disciplines that students are taught in junior courses. Success in mastering these subjects is an indicator of the professional competence of a future engineer, who, along with the graphic language, owns modern graphic modeling software. In this regard, it is necessary to improve the design training of future specialists in the field of engineering and technology, to bring educational work closer to real practice of design and development.

An effective tool for integrating the theoretical foundations of geometric modeling and modern CAD tools is project training, which implements a competency-based model of graphic education [4]. The innovativeness of the new technology lies in the improvement of practical training based on a harmonious connection between theory 
and practice, when practical tasks prompt the student to constantly "obtain" the required information through the electronic learning environment (EOS). For this purpose, comprehensive tasks are developed that integrate various sections of the discipline and imitate professional educational activities [5].

With the help of digital technologies, it is necessary to fill the learning environment with a sufficiently wide and voluminous information material, as well as provide the opportunity for each student to be included in the online process of using all available resources, educational, reference, methodological and other information. Moreover, the amount of information should be regulated by the requirement of its optimality for the student's request. The information provided should not confuse the student, but provide the opportunity for free orientation and collection of necessary information, allowing the student to independently determine the totality of conditions for implementing the project plot [1].

\section{Digital Environment of Project-Oriented Teaching}

Currently, at Perm National Research Polytechnic University, the GGT course is implemented as part of the integrated discipline Engineering Geometry and Computer Graphics. The structural model of the GGT course of filling traditional education with technological innovations is presented in Fig. 1.

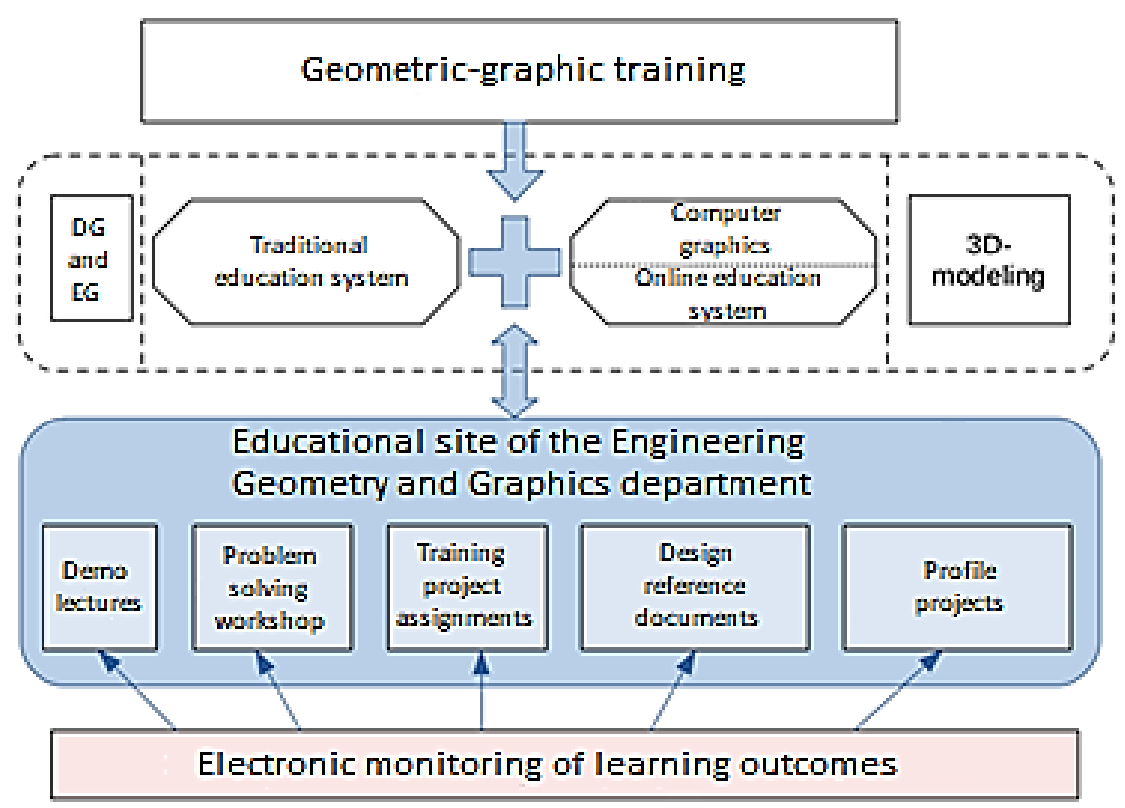

Fig. 1. Scheme for implementation of GGT in digitalization 
As innovations, electronic educational resources are considered, including threedimensional modeling and project training [3, 4], allowing to bring the learning process of students closer to their future professional activities. In the educational process, the main directions are identified in which the unified programs of GGT are implemented. They include: presentation of theoretical material; solution of practice-oriented tasks; individual design tasks; development of training design documentation; automated quality control of training.

The theoretical base of the geometric foundations of the discipline (lecture course), provides students with acquisition of knowledge competencies. Traditional training is supported by modern capabilities of computer technology, which are used in preparation of illustrative electronic material. For independent work of students, an electronic textbook is used.

For practical implementation of the basic theoretical knowledge received by students and their acquisition of skills to solve practice-oriented problems, 2D and 3D technologies are currently used. In this case, the prepared educational resource is in demand - an electronic workshop, which presents a base of geometric problems with creative content. A practical comparison of the capabilities of both technologies, as well as comparative analysis of the advantages and disadvantages of each of them in solving applied geometric problems, can be useful for students at this stage [5].

An important component of the digital learning environment is organization of monitoring the success of mastering the curriculum. Digitalization, based on broad capabilities of modern information and communication technologies, provides innovative opportunities for assessing educational results. Automation of control of students' knowledge and skills in the self-training mode and control measures allows organizing end-to-end monitoring of student performance at all stages of mastering the discipline, systematizing students' independent work, as well as increasing students' motivation and interest in high-quality acquiring the program. A large amount obtained in the course of monitoring educational results can be processed automatically, which allows timely development of corrective impacts on the current situation within the framework of subject training in general, in student groups and the performance of a particular student $[6,7]$.

A comprehensive assessment of the formation of subject competencies is carried out on the basis of activity technologies, which can also be controlled using electronic resources. For organizing practical orientation of the educational process, design tasks for developing algorithms for geometric modeling of virtual objects that have real prototypes in the field of their future professional activity are important. Work with such specialized facilities contributes to initial formation of the professional competencies of future graduates already at the initial stage of mastering the educational program of a certain training direction [8].

The readiness of students for design activity is formed when performing a comprehensive design task that integrates various sections of the discipline and simulates real design activity. Organization of support for students' work at a project requires a more complete set of technological communication and information tools that would help them manage their design process based on the principle of personalization. This final task for the training course is carried out as part of the 
students' independent work, and information support for its implementation is carried out through the electronic learning environment [5]. This section includes all the required information and reference resources, including highly specialized libraries, a control system for the progress of the assignment, as well as an operational consultation channel for communication with the teacher if the student has difficulties in design.

Table 1 presents an example of meaningful options for design tasks with methodologically different approaches. These variants of execution of project tasks allow to take into account students' preferences, their level of geometrical knowledge, personal creativity and degree of formation of digital competence.

Table 1. Methods for implementing design tasks.

\begin{tabular}{|c|l|l|}
\hline $\begin{array}{c}\text { Execution } \\
\text { option }\end{array}$ & $\begin{array}{l}\text { Terms of Reference. Initial data } \\
\text { general view of the "Valve" } \\
\text { product, create models of } \\
\text { components and a model of the } \\
\text { product as a whole }\end{array}$ & Created component models \\
\hline 1 &
\end{tabular}

The contents of the assignment may take into account the direction of training. For example, for mechanical students, it is planned to develop an assembly unit based on 3D technology design documentation, which is an analogue of a clamping device for machining parts. 


\section{GGT in Conditions of Self-Isolation}

The new stage of transition to digital technology training came under the regime of isolation in order to prevent COVID infection. During this period, full online training in the discipline "Engineering geometry and computer graphics" was organized for 1,056 full-time and part-time university students. Table 2 shows the list and purpose of electronic resources used in implementing the discipline program online.

Table 2. Application of electronic resources as part of online learning

\begin{tabular}{|c|l|l|}
\hline № & \multicolumn{1}{|c|}{ Type and name of software } & \multicolumn{1}{|c|}{ Application in distant education technologies } \\
\hline 1 & $\begin{array}{l}\text { The site of the department } \\
\text { http://dgng.pstu.com/ } \\
\text { CMS Moodle web interface at } \\
\text { https://do3.pstu.ru }\end{array}$ & $\begin{array}{l}\text { Placement of teaching materials for self-study by } \\
\text { students - tasks, methods of solution, reference } \\
\text { books, test tasks in all sections and questions for } \\
\text { certification in the discipline }\end{array}$ \\
\hline 2 & $\begin{array}{l}\text { Web interface in the e-conference } \\
\text { BigBlueButton on the site } \\
\text { https://bigbluebutton.pstu.ru }\end{array}$ & $\begin{array}{l}\text { Holding a web conference with students for } \\
\text { consulting and receiving assignments in the form } \\
\text { of interview. }\end{array}$ \\
\hline 3 & $\begin{array}{l}\text { Online service on the site } \\
\text { https://lightpdf.com }\end{array}$ & $\begin{array}{l}\text { Creating and editing PDF files from many } \\
\text { different formats. }\end{array}$ \\
\hline 4 & $\begin{array}{l}\text { Online service on the site } \\
\text { https://disk.yandex.ru }\end{array}$ & $\begin{array}{l}\text { Cloud data storage for uploading, storing and } \\
\text { transferring large files and directories. }\end{array}$ \\
\hline 5 & Software for Windows - PicPick & $\begin{array}{l}\text { Creating and editing screenshots with the ability } \\
\text { to comment on image elements. }\end{array}$ \\
\hline 6 & Software for Windows - XnView & Viewing and simple editing of the image. \\
\hline 7 & Software for Windows - 7-Zip & $\begin{array}{l}\text { Packing and unpacking large files and directories } \\
\text { for sending by email and cloud services. }\end{array}$ \\
\hline 8 & $\begin{array}{l}\text { Software for Windows - CAD } \\
\text { KOMPAS-3D }\end{array}$ & $\begin{array}{l}\text { Students fulfilling assignments regarding the } \\
\text { creation of 3 D - models and associative drawings } \\
\text { with the possibility of design documentation in } \\
\text { accordance with ESKD standards and conversion } \\
\text { of graphic work into images and PDF files. }\end{array}$ \\
\hline 11 & Software for Windows - Viber & $\begin{array}{l}\text { An Internet browser for connecting to the above } \\
\text { web interfaces and online services. }\end{array}$ \\
\hline 9 & $\begin{array}{l}\text { Software for Windows - Mozilla } \\
\text { Firefox }\end{array}$ & $\begin{array}{l}\text { Messaging with attachments, by email, between } \\
\text { teachers and students. Convenient for receiving a } \\
\text { large number of files for subsequent verification. }\end{array}$ \\
\hline Thunderbird & $\begin{array}{l}\text { online between teachers and students. Convenient } \\
\text { for online consultations and student group alerts } \\
\text { of upcoming training sessions and other events. }\end{array}$ \\
\hline & & indows - Mozilla
\end{tabular}

The most time-consuming learning process is associated with remote verification and finalization by students of individual graphic tasks performed in the KOMPAS-3D program. For example, only for student groups of the Faculty of Electrical Engineering 
(183 persons) for 2.5 months isolation the teachers obtained from students, generated and sent back, with notes and remarks about 2000 files (both single-and multi-page). Files from students were accepted in the format of images (*.jpg, *.png), in the format PDF and in format of KOMPAS-3D (*.m3d, *.a3d, *.cdw, *.spw). To check and fill out the corresponding notes on the drawing, sketch or specification, the files were opened in the corresponding software, and the tools and notes were applied with this software.

With such an organization, we note the great efficiency with which a student receives information on checking his assignments and additional consultation. Compared with classroom work, the volume of exchanged information increased 3-4 times. But this, in turn, translates into an additional burden on the teacher.

In general, GGP Online revealed the following negative moments:

1. Inability of some students to install the required software (CAD KOMPAS-3D and editor/virtual printer PDF format files).

2. Multiple cases when students provide graphic works copied from other students. 3. Cases of unauthorized persons or other fellow students performed verification tests and laboratory work carried out remotely at a specific and limited time have been identified. Identification of such work leads to the need of a "face to face" video conference with identity proof.

4. The increase of the current educational information and the need to check it from the PC screen for almost the entire working day is fraught with the occurrence of professional diseases by teachers conducting GGT online.

According to the authors, for further perfection of online education and development of electronic resources of subject teaching it is necessary:

- To change the calculation methodology and redistribute the load for teachers conducting online training, taking into account specifics of the subject area;

- To improve the methodology of remote monitoring of the planned educational results in the online acquisition of the discipline;

- To improve the system of remote communication and student identification during planned control activities;

- To expand the bank of test tasks in the discipline and options for individual tasks or the variability of their performance;

- To enhance automatic control by software sites with hosted assignments and tests on identification of IP User URLs, comparison with the previous entry, ban of addressing to complementary pages, etc.

- To develop methods of analyzing and monitoring the "plagiarism" and "copypaste". As an option, to create software expert system with the ability to analyze a large amount of various information (Big Data).

- To identify key (reference) points of the learning process online in order to avoid its profanation with a mandatory personal interview of a teacher with a student, which can be in a classroom, as well as remote, via video link, with proof of identity. 


\section{References}

1. Kim, I.: Competent education in an innovative format. In: Higher education today, No. 11, pp. 12-18 (2018).

2. Petrova, V., Larionova, A.: Individualization of education in mixed learning as a predictor of professional development of a future specialist. In: Open and Distance Education, No. 4, pp. 32-39 (2018).

3. Amirjanova, I., Vitkalov, V.: The current state of development of geometric- graphic culture and the competence of future specialists. In: Vector of Science of Togliatti State University, No. 2-2, pp. 26-31 (2015).

4. Alexandrova, E., Nosov, K., Stolbova, I.: Practical implementation of project-oriented activities of students in the course of graphic training. In: Open Education, No. 5, pp. 55-62 (2015).

5. Stolbova, I., Aleksandrova, E., Kochurova, L.: The logic of innovation in graphic education. In: Open and distance education, No. 2, pp. 26-34 (2019).

6. Kochurova, L., Kuznetsova, L., Stolbov, O., Stolbova, I.: Quality monitoring of graphic training based on an automated control system. In: Problems of the quality of graphic training of students in a technical university: traditions and innovations, vol. 1. pp. 304-320 (2017).

7. Gitman, M., Danilov, A., Stolbov, V.: Assessment of the level of competence formation of a university graduate. In: Open Education, No. 1, pp. 24-31 (2014).

8. Stolbova, I., Aleksandrova, E., Kochurova, L., Nosov, K.: Profile aspects of graphic education at a polytechnic university. In: Higher Education in Russia, vol. 28, No. 3, pp. 155-166 (2019). 